0 ld habits die hard after years of getting up early with the African sun, but it's not so easy in the depths of an English winter. Nevertheless I'm usually up soon after $5 \mathrm{am}$. It's the best time of the day for thinking and preparing for the day ahead. There is one absolute 'must' each day and that is to make a list of the 'jobs to do'. I'm famous for my lists as well as much teased.

Breakfast is a cup of black coffee before the drive into Bath. It is a 12 mile journey and on summer days can be glorious, but somehow the narrow country lanes are not quite the same in the dark and rain of the winter months. Another cup of coffee, and a quick look at the emails whilst a member of the team checks the 'dom. boxes' before we head out on domiciliary visits.

My car is somewhat old and battered, a 406 estate. It's good for transporting the weighty dom. kit but it can be a nightmare to park in the narrow, crowded, one-way systems in Bath.

I split my time between working in the surgery, domiciliary visits and working at the local hospital seeing patients referred in to the hospital, either in outpatients or in theatre.

One of the commonest reasons for a call to see a new patient in a care home is because their dentures have been lost, especially those with dementia. Care home staff have little idea of the disaster this is for the patient, the family and the dentist and simply imagine we can rustle up a new set that will be a perfect fit in one or two visits. They don't understand that even if we manage to make technically well fitting replacements, they will never be the same or as good as the set that the patient has had for the last 30 years.

My partners on these visits, the dental nurses, enjoy these domiciliary calls. It gives them a whole new perspective on the realities of how life for the frail elderly in care can be. There are often deep philosophical discussions to be

\section{MUCH TO SMILE ABOUT}

Elizabeth Robb (Liz) is a Senior Special Care Dentist with the University Hospitals Bristol NHS Foundation Trust based in Bath. In 2012, Liz was awarded a Fellowship by the National Institute for Health and Care Excellence, a first

for dentistry. Having qualified at University College, London, Liz worked in Zimbabwe for over 25 years. Liz and her family now live in Temple Cloud, a small village in Somerset.

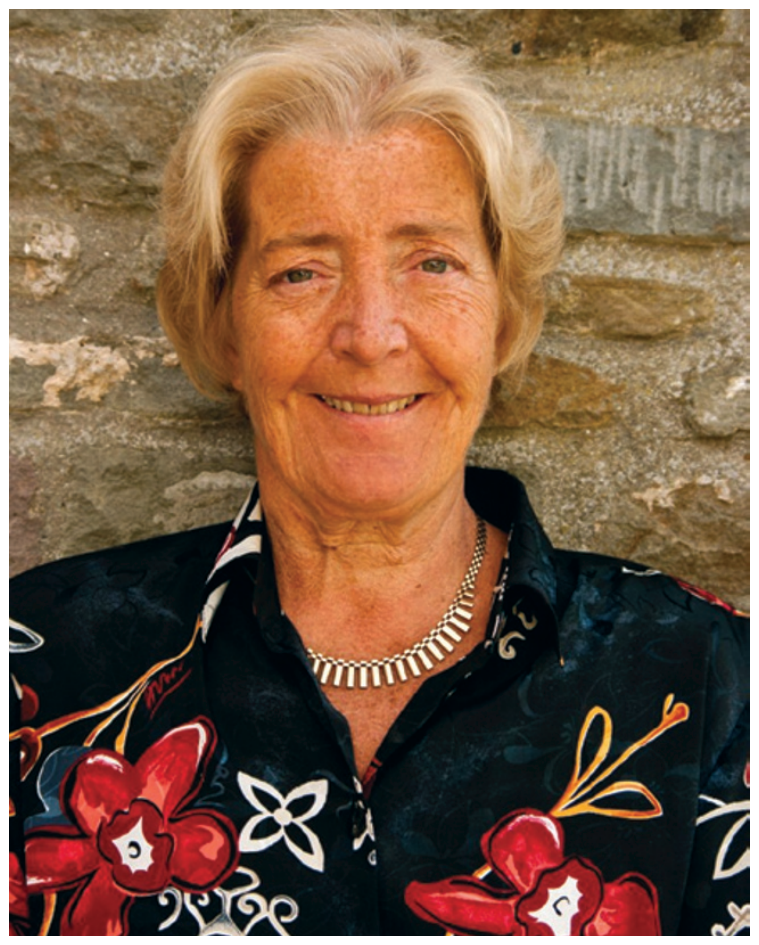

had on the way back on the subject of living wills or 'DNR' affirmations in a set of care notes. Amidst the sadness of working with these very special patients we often find much to smile about.

In the surgery we have plenty of room for even the biggest electric wheelchair as well as a hoist for those unable to transfer to the dental chair, and I don't suppose it will be long before we also have a bariatric dental chair available. I see a wide variety of referrals from the very small anxious child, to the medically compromised of all ages, to those with learning difficulties of all types, to those with diverse mental health problems. They provide us with some very challenging moments.

Our therapist, Josie, has a special way with everyone - they all love her to bits. She must have saved the need for many a general anaesthetic with her gentle ways.

Two or three times a month I work at the hospital seeing those patients who usually require a general anaesthetic for their treatment as they are unable to cooperate in any other way. It is a real one stop dental shop for everything to be done at one time, and can take several hours. Consent issues and best interest meetings that are often required under the Mental Health Act can be extremely time consuming but the lifelong dedication of the parents or carers for these patients certainly puts into perspective any problems I have.

Lunch is very much taken on the run. A big Sainsbury's 100 metres away doesn't help resist temptation, and their fresh jam doughnuts are truly scrumptious.

As part of the salaried service, I realised soon after joining that I would need some postgraduate qualifications, not an easy task having qualified in '76. I completed the Bristol Dip. in Postgraduate Dental Studies and the new RCS Dip. in Dental Health Services Leadership and Management. It was the latter of these two qualifications that has allowed me to spread my wings. Appointed in 2012 as the first dental Fellow with NICE, I have been able to meet with and hopefully influence in a small way the great and the good of the medical and dental worlds.

There will be plenty of time to do things outside dentistry when I am put out to grass. Fortunately my husband and sons, my employer and my super staff have all supported me along the way. The village horticultural society and flower show still keep me busy as do school governor activities and supporting the local church.

If I had the chance to change my career, I would be a gardener, although ideally I would be my much loved and very spoilt cat. No, I don't enjoy kneeling by a chairbound patient only to discover I have wet knees and the catheter is leaking, but... In reality, the variety and challenge of special care dentistry suits me fine. I'd like to think that if I ever need the skills of a special care dentist, they would still be around for me. 